удк $343.3,343.352 .7$

Ю. Н. Румянцева

Всероссийский государственный университет юстиции (РПА Минюста России), Иркутский институт (филиал), г. Иркутск, Российская Федераиия

И. М. Середа

Всероссийский государственный университет юстиции (РПА Минюста России), Иркутский институт (филиал), г. Иркутск, Российская Федерация

\title{
О ВОЗМОЖНОСТИ УГОЛОВНОЙ ОТВЕТСТВЕННОСТИ ЮРИДИЧЕСКИХ ЛИЦ ЗА ЗЛОУПОТРЕБЛЕНИЕ ДОЛЖНОСТНЫМИ ПОЛНОМОЧИЯМИ: СРАВНИТЕЛЬНО-ПРАВОВОЙ АСПЕКТ
}

\begin{abstract}
АНнотАЦИя. На современном этапе развития законодательства ряд провозглашенных приоритетов и целей развития правовой системы остается не обеспеченными юридическими ресурсами. Авторами делается вывод, что действующее российское законодательство в области противодействия преступности юридических лиц не только не отвечает мировым стандартам, но фактически не позволяет вести борьбу с этим явлением. В статье обосновывается, что в качестве уголовно-правовой меры воздействия на предупреждение должностных злоупотреблений следует рассматривать уголовную ответственность юридических лиц. Авторами предпринята попытка сравнительного анализа нормативно-правовой базы Российской Федерации (в том числе проектов ФЗ) и Уголовного кодекса Франции в сфере внедрения и применение института уголовно-правового воздействия в отношении юридических лиц. Предлагается дополнить перечень основных и видов мер уголовно-правового характера запретом на участие в публичных торгах (государственных контрактах), а конфискацию имущества, которое было получено в результате совершения преступления, назначать как дополнительный вид мер уголовно-правового характера. Кроме того, авторы приходят к выводу, что юридическое лицо может выступать и потерпевшим при злоупотреблении должностными полномочиями со стороны власти.

кЛЮчЕВЫЕ СЛОВА. Международные нормы права; противодействие коррупции, уголовная ответственность юридических лиц; злоупотребление должностными полномочиями; зарубежный опыт правового регулирования; юридическое лицо как потерпевшая сторона.

ИНФОРМАЦИЯ О СТАТЬЕ. Дата поступления 05 июня 2017 г.; дата принятия к печати 19 марта 2018 г.; дата онлайн-размещения 09 апреля 2018 г.
\end{abstract}

Yu. N. Rumyantseva All-Russian State University of Justice, Irkutsk Institute (branch), Irkutsk, Russian Federation

I. M. Sereda

All-Russian State University of Justice, Irkutsk Institute (branch), Irkutsk, Russian Federation

\section{ANALYSIS OF LIFE QUALITY OF CIVILIANS LIVING IN ARMED CONFLICT ENVIRONMENT}

ABSTRACT. At the current stage of the legislation development, a number of declared priorities and objectives of the legal system development remains unprovided by legal

(C) Ю. Н. Руляниева, И. М. Середа, 2018

\section{Baikal Research Journal}

электронный научный журнал Байкальского государственного университета 
resources. The authors conclude that the current Russian legislation in the field of counteracting the criminality of legal entities not only does not meet the world standards, but actually does not allow to combat this phenomenon. The article substantiates that the criminal liability of legal entities should be considered as a criminal legal enforcement action to prevent the abuse of power. The authors make an attempt to use the comparative analysis of the regulatory framework of the Russian Federation (including the projects of the Federal Law) and the Criminal Code of France in the field of implementation and application of the institution of the criminal law influence on legal entities. The article proposes to supplement the list of the main types of criminal law enforcement actions with a ban on participation in public markets (state contracts), and with confiscating the property obtained as a result of the commission of crime, as an additional type of a criminal law enforcement action. In addition, the authors conclude that a legal entity can also act as a victim in the abuse of power by the authorities.

KEYWORDS. International law; anti-corruption; criminal liability of legal entities; abuse of power; foreign experience of legal regulation; legal entity as a victim.

ARTICLE INFO. Received June 05, 2017; accepted March 19, 2018; available online April 09, 2018.

Российское общество все еще развивается в условиях дефицита современной правовой базы, в результате чего ряд провозглашенных приоритетов и целей развития правовой системы остается не обеспеченными в достаточной мере юридическими ресурсами.

Безусловно, на современном этапе развития законодательства имплементация норм международного частного права в российскую правовую систему осуществляется во всех отраслях права.

Предупреждение злоупотребления должностными полномочиями регламентировано международными и внутригосударственными правовыми актами. Международное право устанавливает материально-идеологические границы противодействия должностным злоупотреблениям, в рамках которых национальное право регулирует и охраняет общественные отношения при осуществлении государственной службы и службы в органах местного самоуправления.

Для полноценного и эффективного действия международных норм необходимо непосредственное включение их в российские законодательные акты и создание соответствующего механизма реализации этих норм [1, с. 3-4].

В международном частном праве России очень заметно влияние общих идей и принципов конституционализма. В правовой системе России центральным положением в этой области является норма о соотношении международного и внутригосударственного права, закреплённая в части 4 статьи 15 Конституции Российской Федерации: «общепризнанные принципы и нормы международного права и международные договоры РФ являются составной частью ее правовой основы». Таким образом, закрепляется приоритет норм международного частного права над нормами внутреннего права.

Реализация данного приоритета на практике не осуществляется. В УК РФ необходимые изменения и дополнения до сих пор не внесены. Действительно ст. 3 УК РФ определяет: «преступность деяния, а также его наказуемость и иные уголовно-правовые последствия определяется только настоящим Кодексом». То есть, в соответствии с ч. 1 ст. 1 УК РФ перечень преступных деяний не может быть установлен никаким правовым актом, кроме опубликованного и вступившего в силу уголовного закона [2].

Более того, положения некоторых базовых международных правовых актов в сфере противодействия коррупции, злоупотреблению должностными полномочиями (Конвенции ООН против транснациональной организованной преступности,

\section{Baikal Research Journal}

электронный научный журнал Байкальского государственного университета 
Конвенции ООН против коррупции и Конвенции об уголовной ответственности за коррупцию), уже подписанные и ратифицированные, так и не включены в российское законодательство или вошли в него не в полном объеме, что затрудняет использование их в правоприменительной практике.

Так, рекомендациями данных Конвенций предусмотрена обязанность государств-участников ввести уголовную ответственность юридических лиц за причастность к определенным видам преступлений. Как известно, в настоящее время уголовная ответственность юридических лиц в России отсутствует. Следовательно, действующее российское законодательство в области противодействия преступности юридических лиц не только не отвечает мировым стандартам, но фактически не позволяет вести борьбу с этим явлением.

Аналогичную позицию занимают и правоприменители, подчеркивая особую значимость и необходимость внедрения института уголовной ответственности юридических лиц в РФ и приглашая к дискуссии по данному вопросу. Так, 27 апреля 2017 года на совместной коллегии следственных комитетов РФ, Белоруссии и Армении, Председатель Конституционного суда РФ Владимир Зорькин отметил, что «отсутствие уголовной ответственности юридических лиц в России порождает определенные проблемы», связанные с невозможностью проведения оперативно-разыскной деятельности при раскрытии экономических правонарушений юридических и вследствие этого общей недостаточной эффективностью данных мероприятий [3].

Председатель Следственного комитета РФ Александр Бастрыкин неоднократно высказывался о целесообразности введения уголовной ответственности юридических лиц в РФ, отмечая ее возможную эффективность при борьбе с коррупционными преступлениями [4-6].

В перечень вопросов, требующих решение, СК РФ включены положения, определяющие основания уголовной ответственности юридических лиц, круг организаций, подлежащих уголовной ответственности, а также, виды наказаний в отношении виновных организаций и основания освобождения их от наказаний, правовые последствия осуждения юридических лиц. Кроме того, требуется сформировать уголовно-процессуальный и уголовно-исполнительный механизм реализации соответствующих уголовно-правовых норм.

Трудно не согласиться с тем, что нормы об уголовной ответственности юридических лиц вообще, составы преступлений и определение меры наказания, в том числе за злоупотребление властью, должностными полномочиями, не возникнут сами собой. Существенную помощь в их формулировании может оказать изучение и использование зарубежного опыта правового регулирования уголовной ответственности юридических лиц.

Исторический и сравнительный анализы законодательства зарубежных стран показывают последовательное развитие указанных норм (в некоторых государствах) на протяжении нескольких веков, что привело к формированию специфических и развитых институтов уголовной ответственности юридических лиц. Наличие исследований в этой сфере, позволяет максимально учесть зарубежный опыт при внедрении норм об уголовной ответственности юридических лиц в России и оптимальным образом урегулировать соответствующие правоотношения. Тем более, что для современного права характерны процессы унификации, непосредственно затрагивающие и право уголовное [7, с. 12].

Опыт Франции по внедрению данного института представляет для нас особый интерес, является значимым. Российское и французское уголовное право характеризует близость основных принципов и институтов, общность главных концептуальных идей. Дискуссия, развернувшаяся в период обсуждения нового УК Фран-

\section{Baikal Research Journal}

электронный научный журнал Байкальского государственного университета 
ции в конце 1980-х гг., была плодотворной, а в России вопрос целесообразности внедрения института уголовной ответственности юридических лиц остается все еще нерешенным.

Главный аргумент российских противников введения уголовной ответственности юридических лиц совпадает с французскими. Юридическое лицо действует только посредством своих представителей, его деяние не может иметь морального элемента, т.е. юридическое лицо не может совершить преступное деяние виновно. Другое серьезное возражение связано с принципом личной ответственности и принципом индивидуализации уголовной ответственности и наказания.

Признак самостоятельности ответственности является обязательным признаком юридического лица, т.е. последнее признается специфическим субъектом права, в принципе способным самостоятельно отвечать за правонарушения. Этот элемент обязательно включается в структуру его правоспособности (деликтоспособность). И если юридическое лицо однозначно может подлежать такому виду юридической ответственности, как гражданско-правовая, значит, оно может подлежать и другим видам юридической ответственности, например административной или уголовной $[8$, с. 35$]$.

O том, что ответственность юридических лиц вполне может сосуществовать с принципом личной виновной ответственности и дополнять его, писал А. В. Наумов [9, с. 183]. Очевидно, что юридическое лицо способно отвечать в уголовном порядке.

Вместо Уголовного кодекса РФ санкции за причастность юридического лица к преступлению содержатся в законодательстве об административных правонарушениях, например ст. 19.28 КоАП РФ (незаконное вознаграждение от имени юридического лица) устанавливает ответственность юридического лица за причастность к преступлениям, предусмотренным ст. 201 УК РФ (злоупотребление полномочиями) и ст. 291 УК РФ (дача взятки) ${ }^{1}$.

Действительно, статистика по привлечению к ответственности за незаконное вознаграждение от имени юридического лица выглядит впечатляюще и говорит о практике применения вместе с уголовной ответственностью физических лиц, также и штрафов в отношении «сотрудничавшей с коррупционером фирмой» [10].

Так, за период с 2014 по 2016 годы по постановлениям прокуроров к административной ответственности по данной статье в РФ привлечено более тысячи юридических лиц. Общая сумма судебных штрафов превысила полтора миллиарда рублей [11].

В частности, по данным портала Судебного департамента при Верховном Суде РФ $\Phi^{2}$ судами общей юрисдикции по ст. 19.28. КоАП РФ в 2014 году вынесено 244 различных судебных решения, в 2015 году - 431 решение, 2016 году 430 решений. Общая сумма назначенных штрафов составила 1,906 млрд рублей, в частности, в 2014 году $-509,06$ млн рублей, в 2015 году $-729,28$ млн рублей, в 2016 году - 678, 28 млн рублей.

При этом, имеющийся зарубежный опыт является просто не сопоставимым с отечественным. Так, весьма показателен пример, когда власти Германии за доказанные взятки компании Siemens в Литве, России и Нигерии на общую сумму в 12 млн евро наложили на эту фирму штраф в размере 201 млн дол. США. Кроме того, по гражданскому иску компания Siemens выплатила Комиссии по ценным бумагам и биржам США 350 млн дол. и еще 450 млн дол. - по уголовному иску

${ }^{1}$ Проект федерального закона «О внесении изменений в некоторые законодательные акты Российской Федерации в связи с введением института уголовно-правового воздействия в отношении юридических лиц». URL: http://www.sledcom.ru/discussions/?SID=1273 (дата обращения: 01.05.2017).

${ }^{2}$ URL: http://www.cdep.ru/.

\section{Baikal Research Journal}

электронный научный журнал Байкальского государственного университета 
Министерства юстиции США. С учетом других компенсационных выплат коррупционные нарушения стоили этой компании 1 млрд 180 млн долл.США [12, с. 56].

Вместе с тем, при таком правовом подходе, который сложился в РФ, участие физического лица в преступлении рассматривается как общественно опасное деяние, а юридического лица - лишь как административный проступок, что не соответствует той общественной опасности, которая возникает при участии в преступном событии юридического лица, воля которого направлена на достижение преступного результата.

Во Франции данная дискуссия закончилась выработкой условий наступления уголовной ответственности юридических лиц. Так, в соответствии со ст. 121-2 УК Франции юридические лица, за исключением государства, подлежат уголовной ответственности в соответствии с положениями статей $121-4-121-7$ и в случаях, предусмотренных законом или регламентом, за преступные деяния, совершенные в их пользу органами или представителями юридического лица. Так, юридические лица могут быть привлечены к уголовной ответственности практически за все преступления и проступки против собственности. Юридическому лицу, в случае причастности, может быть предъявлено обвинение в краже, укрывательстве, вымогательстве, мошенничестве, отмывании денег, а также злоупотреблении властью.

Вместе с тем, Уголовным кодексом Франции предусмотрена целая система специальных наказаний для юридических лиц, предусматривающая более 10 их видов [13, с. 12, 31]. Так, статья 131-37 УК Франции определяет, что юридическим лицам могут быть назначены следующие наказания, в том числе: прекращение деятельности юридического лица, запрет на участие в публичных торгах (государственных контрактах), запрет постоянный или на срок до пяти лет на публичное привлечение денежных средств, конфискация имущества, которое было получено в результате совершения преступления и т.д. [14, с. 166-167].

При этом, несомненный интерес вызывает тот факт, что органы местного самоуправления и их объединения подлежат уголовной ответственности только за преступные деяния, совершенные при исполнении делегированных полномочий по общественной службе.

Вместе с тем, по УК Франции уголовная ответственность юридических лиц не исключает таковую для физических лиц - исполнителей или соучастников тех же самых деяний ${ }^{3}$.

Таким образом, юридическое лицо может быть субъектом уголовной ответственности, в том числе по составам преступлений, предусматривающим ответственность за злоупотребление должностными полномочиями. Французским опыт представляет интерес для российского законодателя, с точки зрения возможной преемственности норм в УК РФ.

Проектом Федерального закона «О внесении изменений в некоторые законодательные акты Российской Федерации в связи с введением института уголовно-правового воздействия в отношении юридических лиц» (подготовлен СК России) (не внесен в ГД ФС РФ, текст по состоянию на 28.02.2012) (далее Проект Федерального закона), в статье 104.7. предусмотрены следующие виды мер уголовно-правового характера: предупреждение; штраф; лишение лицензии, квоты, преференций или льгот; лишение права заниматься определенным видом деятельности; запрет на осуществление деятельности на территории Российской Федерации; принудительная ликвидация.

3 URL: https://www.legifrance.gouv.fr/affichCode.do;jsessionid=D37DC377B280EDDF42DF29382 52981F8.tpdila13v_2?idSectionTA=LEGISCTA000006149817\&cidTexte=LEGITEXT000006070719\&dat eTexte $=20170511$.

\section{Baikal Research Journal}

электронный научный журнал Байкальского государственного университета 
Так, представляется целесообразным, предусмотреть также в качестве основного вида мер уголовно-правового характера запрет на участие в публичных торгах (государственных контрактах), а конфискацию имущества, которое было получено в результате совершения преступления, назначать как дополнительный вид мер уголовно-правового характера.

Таким образом, ст. 104.7 «Виды мер уголовно-правового характера» Проекта Федерального закона предлагается изложить в следующей редакции, дополнив пунктами: п. 1: «ж) запрет на участие в публичных торгах (государственных контрактах); з) конфискация.»

Вместе с тем, говоря о введении института уголовной ответственности юридических лиц, и уделяя внимание широкому спектру вопросов, в том числе перечню преступлений, в которых юридическое лицо может выступать субъектом, важно учитывать, что юридическое лицо может выступать и потерпевшим при злоупотреблении должностными полномочиями со стороны власти.

Понятие «потерпевший» является одним из ключевых понятий в теории российского уголовного процесса [15, с. 3]. П. С. Дагель выделяет следующие признаки потерпевшего: «Потерпевший - это физическое или юридическое лицо, которому причинен физический, имущественный (материальный) или моральный вред.... Потерпевший - это лицо, которому причинен вред преступлением...если нет преступления, то нет и потерпевшего в уголовно-правовом смысле этого слова" $[16$, с. 18].

Так, основанием для признания юридического лица потерпевшим является причинение вреда как имуществу, так и деловой репутации.

Вред, причиненный деловой репутации коммерческой и некоммерческой организации, подлежит возмещению в уголовном судопроизводстве, что следует рассматривать как одну из разновидностей вреда его имуществу.

Так, недостаточно урегулированными в Проекте Федерального Закона являются вопросы, связанные с основаниями и порядком наделения юридического лица статусом потерпевшего; с осуществлением им своих прав в различных стадиях уголовного процесса.

Авторами представляется целесообразным дополнить Проект Федерального Закона, закрепив рассмотрение юридического лица как потерпевшей стороны при должностных злоупотреблениях.

Уголовный закон, будучи в силу своей правовой природы крайним средством, с помощью которого государство осуществляет реагирование на факты правонарушающего поведения, распространяет свое действие лишь на те сферы общественных отношений, регулирование которых с помощью правовых норм иной отраслевой принадлежности, в том числе норм, устанавливающих административную ответственность, оказывается недостаточным ${ }^{4}$.

В отношении преступлений коррупционной направленности, должностных злоупотреблений этот тезис трудно переоценить. Действительно, административная ответственность, применяемая к юридических лицам, за совершения указанных деяний не соответствует той общественной опасности, которая при них возникает.

В этой связи необходимо использовать международный опыт в борьбе с должностными злоупотреблениями, в частности, введение института уголовной от-

${ }^{4}$ Об отказе в принятии к рассмотрению запроса Курганского городского суда Курганской области о проверке конституционности части первой статьи 3 , статьи 10 Уголовного кодекса Российской Федерации и пункта 3 статьи 397 Уголовно-процессуального кодекса Российской Федерации : определение Конституционного Суда РФ от 10 июля 2003 г. № 270-О // Вестник Конституционного Суда РФ. 2003. № 5. С. 16-17.

\section{Baikal Research Journal}


ветственности юридических лиц, в том числе за должностные злоупотребления. Указанные уголовно-правовые меры, по мнению авторов, будут способствовать повышению эффективности мер в борьбе с коррупционными проявлениями в государстве в целом.

\section{Список использованной литературы}

1. Демин С. Г. Пределы уголовной ответственности юридических лиц в России : дис. ... канд. юрид. наук : 12.00.08 / С. Г. Демин. - Ставрополь, 2014. - 251 с.

2. Комментарий к Уголовному кодексу Российской Федерации (постатейный) / К. А. Барышева [и др.] ; под ред. Г. А. Есакова. - 7-е изд., перераб. и доп. - М. : Проспект, 2017. - 736 с.

3. Зорькин В. Глава КС рассказал об отсутствии уголовного наказания юрлиц [Электронный ресурс] / В. Зорькин // Российская газета. - 2017. - 27 апр. - Режим доступа: https://ria.ru/society/20170427/1493220499.html.

4. Бастрыкин А. Необходимо до суда блокировать счета коррупционера и его родни [Электронный ресурс] / А. Бастрыкин, Н. Козлова // Российская газета. - 2017. 12 апр. - Режим доступа: https://rg.ru/2017/04/12/bastrykin-predlozhil-do-sudablokirovat-scheta-korrupcionera.html.

5. Бастрыкин А. Конфискация как мера наказания является самой действенной для предупреждения коррупции [Электронный ресурс] / А. Бастрыкин, Н. Козлова // Российская газета. - 2014. - 21 янв. - Режим доступа: https://rg.ru/2014/01/21/bastrykin. html.

6. Бастрыкин А. Криминальные фирмы надо судить по Уголовному кодексу [Электронный ресурс] / А. Бастрыкин // Российская газета. - 2011. - 23 марта. — Режим доступа: https://rg.ru/2011/03/22/poziciya-poln.html.

7. Голованова Н. А. Уголовная ответственность юридических лиц в международном и национальном праве (сравнительно-правовое исследование) / Н. А. Голованова, В. И. Лафитский, М. А. Цирина. - М. : Статут, 2013. - 310 с.

8. Качалов В. В. Уголовная ответственность юридических лиц: критический анализ аргументов против / В. В. Качалов // Lex russica. - 2016. - № 12. - С. 32-40.

9. Наумов А. В. Российское уголовное право. Общая часть : курс лекций / А. В. Наумов. - М. : БЕК, 1996. - 560 с.

10. Русецкий А. [Интервью начальника управления по надзору за исполнением законодательства о противодействии коррупции] [Электронный ресурс] / А. Русецкий // Генеральная прокуратура Российской Федерации. -Режим доступа: http://genproc.gov.ru/smi/ news/genproc/news-1179999/.

11. Чайка Ю. Интервью Генерального прокурора Российской Федерации [Электронный ресурс] / Ю. Чайка // Генеральная прокуратура Российской Федерации. - Режим доступа: http://genproc.gov.ru/smi/interview_and_appearences/interview/1158961/.

12. Федоров А. В. Уголовная ответственность юридических лиц за коррупционные преступления / А. В. Федоров // Жћурнал российского права. - 2015. — № 1. - С. 5563. - DOI: $10.12737 / 7249$.

13. Крылова Н. Е. Новый уголовный кодекс Франции: (основные черты) : автореф. ... дис. канд. юрид. наук : 12.00.08 / Н. Е. Крылова. - М., 1995. - 40 с.

14. Качалов В. В. Наказания для юридических лиц по уголовному праву зарубежных стран / В. В. Качалов // Известия Тульского государственного университета. Экономические и юридические науки. - 2014. - № 3-2. - С. 164-170.

15. Ширяева Т. И. Юридическое лицо как потерпевший и особенности его участия в уголовном судопроизводстве : дис. ... канд. юрид. наук : 12.00 .09 / Т. И. Ширяева. — Волгоград, 2008. - 227 с.

16. Дагель П. С. Потерпевший в советском уголовном праве / П. С. Дагель // Потерпевший от преступления. - Владивосток, 1974. - С. 18-37.

\section{References}

1. Demin S. G. Predely ugolovnoi otvetstvennosti yuridicheskikh lits $v$ Rossii. Kand. Diss. [Limits of criminal liability of legal entities in Russia. Cand. Diss.]. Stavropol, 2014. 251 p.

\section{Baikal Research Journal}


2. Barysheva K. A., Gracheva Yu. V., Esakov G. A. [at al.] ; Esakov. G. A. (ed.). Kommentarii $k$ Ugolovnomu kodeksu Rossiiskoi Federatsii (postateinyi) [Comment on the Criminal Code of the Russian Federation (by paragraphs)]. $7^{\text {th }}$ ed. Moscow, Prospekt Publ., 2017. 736 p.

3. Zor'kin V. Head of Constitutional Court told about absence of criminal punishment of legal entities. Rossiiskaya gazeta, 2017, April 27. Available at: https://ria.ru/society/20170427/1493220499.html. (In Russian).

4. Bastrykin A., Kozlova N. It is necessary to block the accounts of the corrupt official and his relatives before the court. Rossiiskaya gazeta, 2017, April 12. - Available at: https://rg. $\mathrm{ru} / 2017 / 04 / 12 /$ bastrykin-predlozhil-do-suda-blokirovat-scheta-korrupcionera.html. (In Russian).

5. Bastrykin A., Kozlova N. Confiscation as a measure of punishment is the most effective for preventing corruption. Rossiiskaya gazeta, 2014, January 21. Available at: https:// rg.ru/2014/01/21/bastrykin.html. (In Russian).

6. Bastrykin A. Criminal enterprises should be judged by the Criminal Code. Rossiiskaya gazeta, 2011, March 23. Available at: https://rg.ru/2011/03/22/poziciya-poln.html. (In Russian).

7. Golovanova N. A., Lafitskii V. I., Tsirina M. A. Ugolovnaya otvetstvennost' yuridicheskikh lits $v$ mezhdunarodnom $i$ natsional'nom prave (sravnitel'no-pravovoe issledovanie) [Criminal liability of corporate persons in international and national law (comparative law analysis)]. Moscow, Statut Publ., 2013. 310 p.

8. Kachalov V. V. The criminal liability of legal entities: critical analysis of opposite arguments. Lex russica, 2016, no. 12, pp. 32-40. (In Russian).

9. Naumov A. V. Rossiiskoe ugolovnoe pravo. Obshchaya chast' [Russian Criminal Law. General Part]. Moscow, BEK Publ., 1996. 560 p.

10. Rusetskii A. [Interview with the head of department for supervision over the implementation of anti-corruption legislation]. General'naya prokuratura Rossiiskoi Federatsii= General Prosecutor's Office of the Russian Federation. Available at: http://genproc.gov.ru/smi/ news/genproc/news-1179999/. (In Russian).

11. Chaika Yu. Interview of Prosecutor General of the Russian Federation. General'naya prokuratura Rossiiskoi Federatsii = General Prosecutor's Office of the Russian Federation. Available at: http://genproc.gov.ru/smi/interview_and_appearences/interview/1158961/. (In Russian).

12. Fedorov A. V. Criminal Responsibility of Legal Persons for Corruption-Related Crimes. Zhurnal rossiyskogo prava $=$ Russian Law Journal, 2015, no. 1. pp. 55-63. DOI: 10.12737/7249. (In Russian).

13. Krylova N. E. Novyi ugolovnyi kodeks Frantsii: (osnovnye cherty). Avtoref. Kand. Diss. [New Criminal Code of France: Main Features. Cand. Diss. Thesis]. Moscow, 1995. $40 \mathrm{p}$.

14. Kachalov V. V. Punishments provided for legal entities under criminal law of foreign countries. Izvestiya Tul'skogo gosudarstvennogo universiteta. Ekonomicheskie $i$ yuridicheskie nauki = Izvestiya of the Tula State University. Economic and legal sciences, 2014, no. 3-2, pp. 164-170. (In Russian).

15. Shiryaeva T. I. Yuridicheskoe litso kak poterpevshii $i$ osobennosti ego uchastiya $v$ ugolovnom sudoproizvodstve. Kand. Diss. [Legal entity as a victim and aspects of its participation in criminal proceedings. Cand. Diss.]. Volgograd, 2008. 227 p.

16. Dagel' P. S. The victim in Soviet Criminal Law. Poterpevshii ot prestupleniya [Victim of crime]. Vladivostok, 1974, pp. 18-37. (In Russian).

\section{Информация об авторах}

Рулянцева Юлия Николаевна - кандидат экономических наук, доцент кафедры государственно-муниципального управления и предпринимательского права, Иркутский институт (филиал) Всероссийского государственного университета юстиции (РПА Минюста России), 664011, Иркутская обл., г. Иркутск, ул. Некрасова, д. 4, e-mail: ynrumyantseva@ mail.ru.

Середа Ирина Михайловна - доктор юридических наук, профессор, заведующий кафедрой уголовного права и криминологии, Иркутский институт (филиал) Всероссийского государственного университета юстиции (РПА Минюста России), 664011, Иркутская обл., г. Иркутск, ул. Некрасова, д. 4, e-mail: irina-sereda@mail.ru.

\section{Baikal Research Journal}




\section{Authors}

Yuliya N. Rumyantseva - PhD in Economics, Associate Professor, Chair of State, Municipal Management and Business Law, All-Russian State University of Justice (Russian Law Academy of RF Ministry of Justice), Irkutsk Institute (branch), 4 Nekrasov St., 664011, Irkutsk, e-mail: ynrumyantseva@mail.ru.

Irina M. Sereda -- Doctor habil. in Law, Professor, Head of Chair of Criminal Law and Criminology, All-Russian State University of Justice (Russian Law Academy of RF Ministry of Justice), Irkutsk Institute (branch), 4 Nekrasov St., 664011, Irkutsk, e-mail: irina-sereda@ mail.ru.

\section{Для цитирования}

Румянцева Ю. Н. О возможности уголовной ответственности юридических лиц за злоупотребление должностными полномочиями: сравнительно-правовой аспект / Ю. Н. Румянцева, И. М. Середа // Baikal Research Journal. — 2018. — Т. 9, № 1. — DOI : 10.17150/24116262.2018.9(1).15.

\section{For Citation}

Rumyantseva Yu. N., Sereda I. M. On Possibility of Criminal Liability of Legal Entities for Abuse of Power: the Comparative Legal Aspect. Baikal Research Journal, 2018, vol. 9, no. 1. DOI: 10.17150/2411-6262.2018.9(1).15. (In Russian).

\section{Baikal Research Journal}

